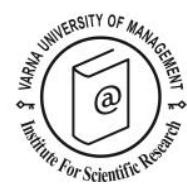

\title{
Brand Value Attributable to Affiliation (BVAA) - a Method for Measurement in a Consortium Context
}

\author{
Mats Carlbäck ${ }^{{ }^{*}}$
}

Received: 25/10/2018 Accepted: 04/06/2019

\footnotetext{
${ }^{1}$ School of Hospitality, Culinary Arts \& Meal Science, Örebro Universitet/Örebro University, Sörälgsvägen 1, S71260 Grythyttan, Sweden. E-mail: mats.carlback@oru.se, Tel: +46 (0)19 302023

* Corresponding author

Coordinating editor: Stanislav Ivanov
}

\begin{abstract}
Hotel affiliation is a debated issue in the hospitality industry. The question is primarily if it adds any financial advantages, and secondly to what extent an intangible asset value is created. Intangibles are per definition difficult both to define and to calculate and the aim with this article is to develop a method, based on earlier studies, to facilitate calculations in a consortium context. This is the least researched affiliation format, but at the same time the preferred option for independent hotel owners seeking strategic advantages for the future.

By identifying the contribution associated with an affiliation as well as incremental costs and including the investment for adapting the property in accordance with the stipulated standards for the affiliation, a method to compute the brand value attributable to affiliation (BVAA) is developed. This study, by using a constructive approach, produces an indicative valuation method (the BVAA calculation method) usable both to assess the financial effect of the brand value associated with a specific brand and for separating intangibles (in this case the BVAA) from the market value.
\end{abstract}

Keywords: Brand Value, Affiliations, Hotels, Consortium, Assessment

Citation: Carlbäck, M. (2019) Brand Value Attributable to Affiliation (BVAA) - a Method for Measurement in a Consortium Context. European Journal of Tourism Research 23, pp. 112-126

\section{Introduction}

In the hotel industry, the concept of brand value is becoming increasingly important in the marketing and strategy contexts. The wellestablished axiom "location, location, location" is to an increasing extent being replaced by the axiom "flag, flag, flag" (Taylor, 1995) as an answer to the question; "What are the three most important factors for a successful hotel operation?" In an era with tremendous growth, international expansion and new and innovative business models the foundations for business decisions need to be specific, applicable and user-friendly- where the phenomena of brand

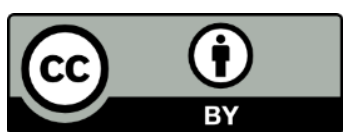

112
This work is licensed under the Creative Commons Attribution 4.0 International (CC BY 4.0). To view a copy of this license, visit https://creativecommons.org/licenses/by/4.0/ 
and branding is one crucial aspect. During the last quarter of a century, the flag (brand) associated with hotel affiliation companies has become one of the most important strategic issues in the hotel industry (Ivanova \& Ivanov, 2015, 2016; Manthiou, Kang, Sumarjan, \& Tang, 2015; O'Neill \& Mattila, 2010). A more complete understanding of, for example the nature, the determinants, the measurement, and the valuation of brand value, would be useful in various context, such as taxation (O'Neill \& Xiao, 2006), strategic decision making (Bailey, 2007; Cai \& Hobson, 2004; Carlbäck, 2010; Carlbäck, 2016; O'Neill \& Belfrage, 2005; Roper, 2018. Rushmore, O'Neill, \& Rushmore, 2013), marketing (Dev, Brown, \& Zhou, 2007; O'Neill \& Mattila, 2010, Seric, Gil-Saura \& Eugenia Ruiz-Molina, 2014), brand management (Prasad \& Dev, 2000), and the concept of trust and affective commitment related to the guests (Seric, Mikulić \& Gil Saura, 2018; Hasni, Salo, Naeem \& Abbasi, 2018). This would be of utmost importance to several categories of users such as owners of hotel properties, management companies, investors, and managers at executive levels in hotel companies.

The vast majority of extant research on hotel and hospitality focuses on affiliation arrangements, such as company owned brands, managements companies, hotel property companies, and franchise companies, with limited focus on the consortium arrangement. Consortium companies currently have a significant and growing market share in the hotel and hospitality market, which is expected to increase even more in the future (Ayazlar, 2016, Martorell Cunill, 2006; Rivet, 2011). The world's largest hotel chain, Best Western, is likely the most well-known consortium company (see http://www.bestwestern.com). A consortium company is a group of independent hotels, often referred to as marketing organisations or referral chains, joined together to improve certain aspects of operations, pinpointed by Seric et al. (2014) as relevant factors. It could be the development of a loyalty card system, a central reservation system, a central purchasing system, or pooled marketing and sales activities (Seric et al. 2014). In this arrangement, the independent hotels will retain their operational freedom, while at the same time enhance their presence on the market by the added strength associated with collective resources, knowledge, know-how etc. Another characteristic of the consortium arrangement is that its affiliated members are not required to adhere to standardised operating procedures in the same ways as the business format of franchising.

An important task of hotel management is to assess the financial value associated with consortium company affiliation. However, a literature review showed that there is a lack of methods for evaluating the financial value in this context. The main objective of this study is - drawing on principles of financial management - to develop a method for calculating the financial value of belonging to a consortium company for an individual hotel to be used as one part of the assessment process.

The remainder of the paper is organised as follows. The next section discusses the framework/principles used for developing the method. The research method is described in the third section. The fourth section explains the practical usability of the method developed. In the concluding section the results are discussed, highlight the research contribution and practical relevance, and present suggestions for further research.

\section{Framework for method development}

This section presents the framework the study uses to develop a method, which draws on the financial management literature, for calculating the financial value of belonging to a consortium company for an individual hotel.

\section{Hotel affiliation in the consortium context and motivational factors}

With the growing importance of different types of affiliations, there is a trend in the hotel market in that independent hotels are being incorporated in larger organisations. From the individual hotel's perspective, the motivations for this trend is linked to factors such as growth and strategic development, or just to cope with increasing competitive pressure (Ivanova \& Ivanov, 2015b). 
In many advanced economies, affiliations are taking a larger part of the hotel market. Statistics from Euromonitor (2010) show that only $15 \%$ of the world's hotels are considered to be affiliated (owner-operated, management companies, franchise organisations), leaving $85 \%$ as independent hotels. The $15 \%$ does, however, not include hotels affiliated with consortium companies. Surveys have shown that there are major differences in affiliation between geographical regions. The U.S. market, where the affiliation process appears to have developed most, is according to AH\&LA (American Hotel \& Lodging Association, 2011) split between 51\% affiliated and 49\% independent hotels of the hotels registered with AH\&LA. These figures only make a distinction between chain hotels or independent hotels, while hotels affiliated to consortium companies are treated as chain hotels in these reports.

As the consortium company offers a less rigid form of affiliation, where the hotel owner retains much of the control, it suits many entrepreneurs and family owned hotels who value the quality of being independent (Carlbäck, 2012). The degree of involvement varies between the different consortium companies, but often the focal point is the sales and marketing efforts, such as central reservations systems, brand related advertising, and loyalty cards (Lee \& Jeong, (2014). According to earlier studies (Carlbäck 2012), this is the essence of what the independent hotel owners are seeking, but they are at the same time unwilling to give up their independence to be controlled by a remote head office. That would contradict their main objectives with their business ventures, like building something for the family or "a way of life" (Andersson et al. 2002).

\section{Foundations for method development}

Most hotels have a brand, whether the hotel is affiliated or not. The small, completely independent family hotel will have a brand to nourish in the same way as the Waldorf Astoria in New York. As this paper is focusing on consortium companies, the perspective here will be on the financial value directly linkable to brand affiliation or not, i.e. the financial benefits a hotel will gain from affiliate with a specific brand, in terms of both added market value and performance boosting.A method for assessing the financial value should use a net present value (NPV) approach to determine the present value of affiliation (brand) by the discounted (net) sum of cash inflows and cash outflows directly linked to affiliation (brand).

Previous attempts to measure this value have typically ignored the initial investment required for an individual hotel to become affiliation ready. Rushmore (2001) touches on this issue when he highlights the often substantial initial fee payable to the organisation as an entrance fee. This fee could be significant, but is typically discussed only in the context of management contracts and franchise organisations. In the case of a consortium company, there is seldom an initial membership fee payable to the affiliation and therefore this is of no concern for the hotel owner interested in affiliating. Carlbäck (2012) found that the yearly payments payable to the affiliation for the membership were not a major concern for the hotel owners. More important were the initial cash-outlays to fulfil the requirements set out by the consortium company, i.e. to live up to the standards necessary to become a member. Two hotels in Carlbäck's study opted to stay independent based on too high investments to get the property "affiliation-ready". Any attempts to calculate the financial value attributable to the affiliation ought to include initial investments, such as (Martorell Cunill, 2006; Rushmore, 2001b): Adapting the property (increase standards, size of rooms, standard of bath rooms, etc.), addition of facilities and functions (bar, restaurant, spa, etc.), signage and postage, contracts, legal works, lawyers' fees, uniforms, stationary, contracts with suppliers, systems and applications (new computer systems, new management control system, etc.). Several of these investments fall outside the ongoing cash outlays (i.e. cash flows related to already existing operations) and should therefore be treated as investments directly attributable to the membership in the consortium company.

Characteristics of existing methods in the area Within the field of measuring and evaluating the financial value of affiliation there are a limited number of existing methods available, mainly developed within academia. The inclusion 
criteria here will be a focus on measuring the value of belonging to an affiliation from a hotel perspective. Most studies of hotel or brand related valuations indicate that apart from the real estate - the building in which the hotel is operating - the brand represents a significant part of the remaining value (Bailey \& Ball, 2006; O'Neill \& Belfrage, 2005; Tiwari, 2010; Tollington, 2002). The Rushmore method (Häggström, 2012; O'Neill \& Belfrage, 2005; Rushmore, 2004) is based on the assumption that the cost of belonging to an affiliation reflects the market value of that specific affiliation. From the individual hotel owner's perspective this will not suffice, as the affiliation should generate higher revenues than costs, as this is the reason to affiliate and pay fees. In some cases the value associated with the affiliation could be negative, as the costs associated with the affiliation is exceeding the revenues received. This may be due to improper contracts, wrong affiliation for a particular property or other similar erroneous managerial decisions. A negative value associated with the brand is equally important to measure in order to be able to take corrective decisions.

O'Neill \& Belfrage (2005) identified and calculated the financial value of affiliating based on the notion of incremental revenues attributable to affiliating should exceed attributable incremental costs related to the membership in an affiliation. By identifying all incremental revenue, such as rooms sold through central reservation systems, online booking systems, loyalty cards, etc. and deducting all affiliation associated incremental costs (variable cost such as management fees, royalties, and reservation fees) they were able to calculate the financial value of the affiliation. However, O'Neill \& Belfrage (2005) do not include the affiliation imposed adaptation cost (adapt the hotel to the standards required by the affiliation), and this method may therefore be less suitable in a consortium company context, as the adaptation cost could be substantial for the individual hotel seeking the option of affiliating.

A method introduced by Ailawadi, Lehman \& Neslin (2003) measures brand value as brand equity. Their method measures the brand value for a large group of primarily products using the revenue premium approach, i.e. the idea that the brand should produce superior revenue compared to an unbranded product or service. The same approach could then be transferable to services, and also to organisations and affiliations. Ailawadi et al (2003) argue that the revenue premium approach is better than other approaches as it includes future potential and excludes customer surveys. This concept has a lot of bearing for the attempts to create a method for the hotel industry as the revenue premium approach is developed to a contribution premium approach, where the cost behaviour is included as well. A useful method for the aim with this project needs to contain a premium concept, i.e. the contribution attributable to the affiliation and also, as this is seen as important, the outlay connected to the adaptation of the affiliation standards for the hotel.

\section{Comparison of requirements of relevant} method and existing methods

The definition of the concept of financial value associated with a brand varies between sources (Bailey 2007, Dev et al., 2007; O'Neill \& Mattila, 2004). Brand value, i.e. the financial value attributable to the brand, and brand equity are two different, yet closely linked, concepts. Tiwari (2010) explains the differences as follows: brand value is the net present value of future cash flows from a branded product minus the net present value of future cash flows from a similar unbranded product - or, in simpler terms, what the brand is worth to management and shareholders (Tiwari, 2010), while brand equity is a set of perceptions, knowledge and behaviour on the part of customers that creates demand and possibly a price premium for a branded product - i.e. what the brand is worth to the company based on the customer's perception (Tiwari, 2010).

The current study uses Tiwari's definition above and focuses on the financial value of the brand, i.e. the affiliation - the financial value for the hotel owner and for other stakeholders calculated on a NPV basis (Tollington, 2002).

It is uncommon to measure the financial value of the actual brand (as sales or replacement 
value) in an affiliation or chain situation, i.e. try to establish the value of the brand for a business owner or manager - primarily as a strategic tool. It could stem from the issue of not clearly defining brand vs. equity, as the two concepts are used to describe more or less the same functions. Attempts made are often associated with the hotel industry, where chains, consortium companies, and affiliations are important and noticeable factors.

As noted above, the main issue is to calculate the financial value attributable to the affiliation from the individual hotel's perspective, i.e. the discounted (net) sum of cash inflows and cash outflows directly linked to affiliation (brand). It is important to separate the brand value linked to the affiliation from the market value in a consortium company context, as this will be the vital point for consortium company management and for independent hotel owners.

Any hotel contemplating to join an affiliation would anticipate additional incremental revenue flow as a result. An incremental revenue flow that would exceed any incremental costs traceable to the membership, consequently produce a positive value related to the affiliation membership. The possibility of additional incremental revenue leading to financial value creation would be the core concern for the hotel owner, who would be less interested in separating the financial value associated with the affiliation from the property.

By O'Neill and Belfrage's method, which is focused on calculating the intangible asset value with the inclusion of attributable incremental revenue and costs, the intended method is developed further, where the financial value attributable to the affiliation is calculated from a contribution attributable to the affiliation. But as previous research has indicated, the initial investment related to the adaptation process (to become affiliation ready) is a major concern and needs to be included in the method in order to fulfil its purpose. If not, it becomes less usable in a consortium company context where the initial investment to fulfil the standards is of great importance, even if the contribution aspect is similar to the method developed by O'Neill and Belfrage. By integrating elements from the Rushmore method and the O'Neill and Belfrage method, with support from Tiwari's' definition of brand value, a method could be developed. Extraction of values and illustrations of the calculations will be presented below.

\section{Method}

Based on the nature of this work, which falls within management accounting - a constructive approach is used. Kasanen, Lukka \& Siitonen (1993) describe the process of a constructive approach as follows:

1. Find a practical relevant problem which also has a research potential.

2. Obtain a general and comprehensive understanding of the topic.

3. Innovate, i.e. construct a solution idea.

4. Demonstrate that the solution works.

5. Show the theoretical connections and the research contribution of the solution concept.

6 . Examine the scope of applicability of the solution.

The development of the method follows all the points above and can be classified as constructive research as it is a combination of problem solving and demonstration of a theoretical connection. A practical and relevant problem was identified - the lack of a method to measure BVAA in the hotel industry. This research project is divided into two parts; a construction of the method based on existing methods and influences from the literature, and an illustrative test, constructed on actual figures from income statements from two hotels in Sweden. The two parts are performed simultaneously in order to identify and extract the necessary information and valid parameters.

\section{Data}

Two hotels in Sweden were selected to participate and contribute with income statement data to demonstrate that the solution works. The selection was based on finding properties of considerable size and with a strong market presence on different locations. Selection criteria also included membership in one of the larger or more well-known sales and marketing organisations in the region. It was also important to ensure full compliance from 
the hotel owners, as the project requires full transparency, i.e. all figures and reports need to be available for the researcher. This could create a barrier for many hotel owners, as some of this information is considered sensitive. The participants in this project complied fully, but also required anonymity both from an individual hotel perspective and from the affiliations perspective.

The data gathering process presented larger obstacles than initially envisaged, which should be taken into consideration for any future studies. Even though all accounting and paper work were up to standard and the owners were fully engaged in their businesses, the identification of incremental revenue and incremental cost associated with the affiliation proved a challenge to identify and extract. For a more detailed description of the participating hotels see Table 1.

Table 1. Participating hotels and general facts

\begin{tabular}{|c|c|c|}
\hline & Hotel A & Hotel B \\
\hline Rooms & 51 & 74 \\
\hline Built & 1971 & 1983 \\
\hline Rating & $3^{*}$ & $3^{*}$ \\
\hline Employees & 12 & 19 \\
\hline Affiliated/year & 2009 & 2005 \\
\hline Location & City centre & Outskirts of city \\
\hline F\&B Facilities* & $1,2,3,4$ & $1,2,3,4$ \\
\hline NOl/room/year & 6,045 & 20,249 \\
\hline $\mathrm{ADR}^{* *}$ & 608 & 919 \\
\hline Occupancy \% & $63 \%$ & $58 \%$ \\
\hline $\operatorname{RevPAR}^{\star * *}$ & 383 & 583 \\
\hline \multicolumn{3}{|c|}{$\begin{array}{l}{ }^{*} \text { F\&B facilities }={ }^{*} 1=\text { breakfast, } 2=\text { lunch, } 3=\text { dinner, } 4= \\
\text { bar } \\
\text { **ADR }=\text { Average Daily Rate in SEK (average for } 3 \text {-year } \\
\text { period Year } 1 \text {-Year } 3 \text { ) } \\
\text { *** RevPAR }=\text { Revenue per Available Room in SEK } \\
\text { (average for 3-year period Year } 1 \text {-Year } 3 \text { ) }\end{array}$} \\
\hline
\end{tabular}

\section{$B V A A$ - the method}

The BVAA method has been developed from factors identified above with the addition of previously studied factor of importance relating to the specific challenges facing hoteliers contemplating the affiliation format consortium, i.e. the cost associated with adapting affiliation standards.
Consequently, the BVAA (brand value attributable to affiliation) method was developed based on the following factors and input data:

The incremental revenue and cost directly attributable to each hotel's affiliation on an ongoing basis were identified and summarized to a gross profit figure attributable to the affiliation. Detailed income statements for each site were used to identify related incremental revenue and cost. Each post was analysed and evaluated by the manager and the researcher as to its relevance and connection to the affiliation. Any questions or uncertainties were analysed and discussed with respective manager in order to establish if the post should be treated as an incremental revenue or cost related to affiliation. Income statements for three consecutive years were used for each hotel.

For illustrative purposes the key performance indicators (KPI's) for the hotels were also collected as presented in Table 1. The key performance indicators could in this context be used to analyse the reasons to variation in BVAA and possibly to identify corrective actions.

The incremental revenue attributable to affiliating is the gross profit which could be directly traceable to the affiliation belonging, i.e. it would not exist without the flag related to the brand. This could be both the additional revenue relating to the increased flow of business thanks to the increased market presence due to increased and pooled sales and marketing activities and the premium rates resulting from representing a well-known brand. By representing a nationally or internationally known brand the rate structure could be enhanced as the potential guests' willingness to pay would increase. The central reservation systems and negotiation power connected to consortium companies should also affect the incremental revenue stream in a positive way.

Incremental cost attributable to affiliation was identified and calculated based on the gross profit (GP) attributable to the affiliation. As the affiliation revenue streams in consortium are logged independently, it forms a base for fees 
Brand Value Attributable to Affiliation (BVAA) - a Method for Measurement in a Consortium Context.

\begin{tabular}{|lll|}
\hline & $\begin{array}{l}\text { Gross profit- } \\
\text { attributable to } \\
\text { affiliation } \\
\text { method }\end{array}$ & BVAA method
\end{tabular}

Figure 1. The development of the BVAA-method

paid to the affiliation as a fee per booking or reservation made through their channels. The incremental cost is made up of all related incremental costs attributable to the brand, i.e. fees and royalties, but also for reservation systems, marketing material, PR, use of central reservation systems and commission on bookings made. By subtracting the direct costs attributable from the gross profit attributable to the brand, the result produced is an annual gross profit attributable to the affiliation.

The investment associated with the adaption process was identified. The hotel owners were asked to present a summary of estimated posts relevant for the adaptation process at the time of the actual adaptation. The summaries presented were detailed and in the process each item was evaluated as to its direct link to the affiliation. Direct traceable items such as new signage, uniforms, stationary, menus, marketing material were singled out directly as relevant. The same process was carried out for hardware and software necessary for the adaptation in a straight forward manner. In cases where the initial investments were less uniquely related to the affiliation and could carry a residual value even without or after an affiliation period, the sums were evaluated on its individual merit and based on economic life cycle. This could include upgrading of amenities, rooms, bathrooms and other vital parts of a hotel operation and in cases of doubt, the economic life cycle has been evaluated to find out if a residual value will exist after a possible termination of the contract with the affiliation creating a value regardless of the site being affiliated or not. See Table 4 for detailed information regarding factors included herein.

\section{Results}

Calculations of the net contribution attributable to the affiliations are displayed in Table 3, where the gross profit and cost attributable to the affiliation are used. These figures derive directly from the income statement for each hotel respectively and as a part of the rules and regulations associated with the affiliation process, all items directly related to the affiliation are presented as individual items in the statement. The affiliation related gross profit is presented as coming from the affiliation and the affiliation related incremental costs are itemised in the same manner - albeit under different topics based on affiliation.

Reservation fees are posted only for directly related reservations and loyalty night are posted as "free rooms" given to the affiliation in order to be provided to guests who have earned points within the affiliation to qualify for complimentary accommodation. These two are posted on different accounts.

Direct, variable costs (cleaning, laundry, etc.) connected to the "sale" of redeemed loyalty rooms, is deducted from the amount presented in Table 2, to produce a gross profit figure attributable to the affiliation.

Based on the fact that the participating hotels are members of different affiliations, the indicated fees and costs associated with the affiliations are presented differently, mainly due to the agreements signed with the affiliations. The costs presented in Table 2 are all variable from a zero base, and the cost drivers are amounts of rooms sold, bookings achieved, etc. 
Table 2. Calculation of net contribution attributable to the affiliation for hotel $A \& B$, Year $1-$ Year 3

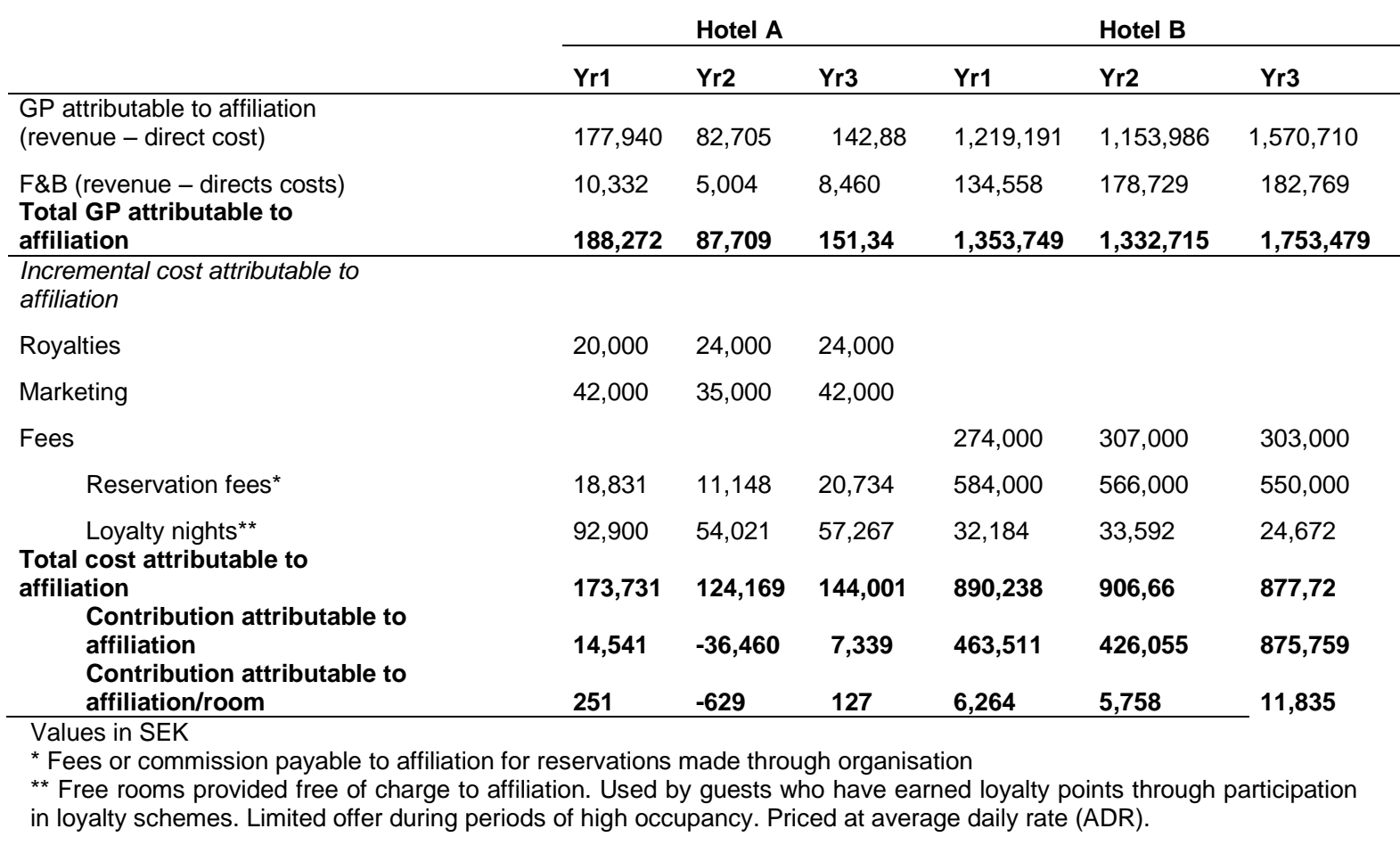

In Table 2 it is possible to identify the figures used in the Rushmore-method, i.e. the costs associated with the affiliation. Grouped together they average SEK 147,000 (173 731, 124169 and 144000 respectively) per year for hotel $A$ during the three years and SEK 891,000 per year for Hotel B. The actual ongoing cost for the membership varies significantly. In the Rushmore-method, these figures would represent the value of affiliation (which will never be negative) and be deducted from the operating cash flow in order to extract the value of the real estate.

Notable is the negative contribution attributable to the affiliation for Hotel A for Yr2, where the contribution dropped considerably from $\mathrm{Yr} 1$. This is partly explained by a slow demand on a regional level in combination with limited response from the affiliation to react to these problems. Still, the amount of loyalty nights given away is high, which increases the costs attributable to the affiliation even if the revenue decreases.

The results produced in Table 2 are contribution attributable to affiliation for each hotel for the three years respectively. In order to calculate the BVAA, a further step is necessary. The contribution attributable to affiliation needs to be divided by the prevailing capitalization rate (cap rates), based on similar investment grades (O'Neill \& Belfrage, 2005). This presents an obstacle as cap rates for intangibles (as BVAA) are not available to the same extent as cap rates for real estate, where these figures are presented in various reports and statistical information (O'Neill \& Belfrage, 2005). We will use O'Neill and Belfrage's (2005) extraction of intangible asset cap rate, based on figures presented in Lloyd-Jones' (2010) report on cap rates in the hotel industry (Lloyd-Jones, 2010).

Cap rate (capitalization rate) is commonly used when calculating property prices and property values. A widely used definition for cap rate is presented by Lloyd-Jones (2010) "An income rate for a total real property interest that reflects the relationship between a single year's net operating income expectancy and the total property price or value; used to convert net operating income into an indication of overall property value." Lloyd-Jones uses historical 
(previous years) operating income figures to establish the cap rate (Lloyd-Jones, 2010). The equation for deriving at property value is expressed as follows:

Cap rate $=$ Net profit $/$ Property value

$\rightarrow$ Property value $=$ Net profit $/$ Cap rate

Cap rates are primarily based and used on real estate, but for this purpose the Yr2 figures from the hospitality consulting firm HVS's (see www.hvs.com) data base will be used, grounded on figures for hotels of similar investment grade. Lloyd-Jones (2010) makes a distinction between major transaction, i.e. hotels with value in excess of 10 MUSD and all transactions. As the two hotels in this study are smaller than the threshold, the cap rate for all transactions will be used. The report (LloydJones, 2010) indicates a decline in cap rate during the last decade and the comparable figure is $9.9 \%$ (this could be compared to a cap rate of $7.5 \%$ for major transactions).

The calculation is based on previous research indicating the following breakdown of a hotel's enterprise value (O'Neill \& Belfrage, 2005), with the inclusion of the latest available cap rate from Lloyd-Jones survey (2010), both for real estate $(8.5 \%)$ and personal property $(15.0 \%)$ :

Table 3. Cape rate

\begin{tabular}{lcc}
\hline Position & $\begin{array}{c}\text { Percent } \\
\text { of value }\end{array}$ & Cap rate \\
\hline Real Estate & $70 \%$ & $8.5 \%$ \\
Personal Property & $10 \%$ & $15.0 \%$ \\
Intangibles & $20 \%$ & $X$ \\
Total & $100 \%$ & $9.9 \%$ \\
\hline
\end{tabular}

The following calculation is used:

$$
\begin{aligned}
& X=(9.9 \%-8.5 \% \times 70 \%-15 \% \times 10 \%) / 20 \% \\
& \rightarrow X=12 \% \text { (rounded) }
\end{aligned}
$$

We can then calculate the gross BVAA from the contribution attributable to affiliation for both hotels:

\section{BVAA (gross) = Contribution $/$ Cap rate $=$ Contribution/0.12}

Table 4 presents the brand value in the same manner to O'Neill \& Belfrage's (2005) 120 calculation of an intangible asset value for company-operated hotels. We find significant variations between the two brands. While the brand connected to Hotel $A$ in this case is merely worth SEK 61,158 based on contribution $\mathrm{Yr}$, the brand used by Hotel $\mathrm{B}$ is worth over MSEK 7 based on contribution Yr3. This would constitute a substantial part of the hotels market value, even if such a valuation is outside the scope of this paper.

These calculations do not include the initial investments. The limitation with O'Neill \& Belfrage's technique in a consortium context is the omission of costs associated with the initial investment in the calculations. And as this clearly is affecting the decisions making for the hotel owners it could add further to the usability.

To include the actual initial investment in the calculation of the BVAA in order to establish the feasibility of affiliation, the initial investment directly attributable to the membership needs to be computed. The discount rate used is the 9.9\% from Lloyds and Jones (2012) statistic mentioned previously.

The above initial investments, Table 5, have been identified for the participating hotels related to the adaptation and consequently presented as discounted value to facilitate a calculation at present values, Table 6 .

By then deducting the discounted value of the initial investment from the previously computed BVAA (gross), it is possible to calculate BVAA for each hotel, i.e. how much the brand is worth in total at a specific year.

From the previously calculated BVAA (gross) the discounted value of the initial investment is deducted to produce the BVAA for each brand respectively, which is presented in Table 7 as Total BVAA. It is worth observing here that the discounted value is computed for each year, and is only valid for that year and should not be summarized for the whole time period. The BVAA (gross and total) value is consequently measured for individual years and the value would only be valid for that specific year in a similar manner as a balance statement. 
Table 4. Calculation of BVAA (gross) based contribution attributable to affiliation. In SEK.

\begin{tabular}{lllllll} 
& \multicolumn{3}{c}{ Hotel A } & \multicolumn{3}{c}{ Hotel B } \\
\cline { 2 - 6 } & Yr1 & Yr2 & Yr3 & Yr1 & Yr2 & Yr3 \\
\hline Contribution attributable to affiliation & 14,541 & $-36,460$ & 7,339 & 463,511 & 426,055 & 875,759 \\
Cap rate & 0.12 & 0.12 & 0.12 & 0.12 & 0.12 & 0.12 \\
BVAA (gross) & 121,175 & $-303,833$ & 61,158 & $3,862,591$ & $3,550,458$ & $7,297,991$ \\
\hline
\end{tabular}

Table 5. Affiliation induced adaptation factors in SEK (investment according to affiliation requirements)

\begin{tabular}{lrr} 
& Hotel A & Hotel B \\
\hline Signage & 26000 & 72000 \\
Uniforms & 18000 & 22000 \\
Stationary & 35000 & 8000 \\
Computer systems & 44000 & 72000 \\
Printing Matters & 35000 & 2000 \\
Marketing material & 17000 & 27000 \\
Refurbishment lobby & 102000 & 12000 \\
Upgrading rooms & 83000 & 210000 \\
Upgrading hall ways & 0 & 87000 \\
Upgrading bar & 0 & 32000 \\
Upgrading kitchen & 0 & 47000 \\
Upgrading conference & 0 & 72000 \\
IT installations & 0 & 7000 \\
Total & 360000 & 670000 \\
\hline
\end{tabular}

Table 6. Discounted value of initial investment (at 12\%) to fulfil affiliation standard as a one-off sum in SEK.

\begin{tabular}{lrr}
\cline { 2 - 3 } & \multicolumn{1}{c}{ Hotel A } & \multicolumn{1}{c}{ Hotel B } \\
\hline Initial investment & $\mathbf{( 2 0 0 9 )} \mathbf{3 6 0 , 0 0 0}$ & $\mathbf{( 2 0 0 5 )} \mathbf{6 7 0 , 0 0 0}$ \\
NPV 2005 & & 670,000 \\
NPV 2006 & 736,330 \\
NPV 2007 & 809,227 \\
NPV 2008 & & 889,340 \\
NPV 2009 & \\
NPV 2010 & 360,000 & 977,384 \\
NPV 2011 & 395,640 & $1,074,145$ \\
\hline
\end{tabular}

Table 7. BVAA computed including discounted value of the initial investment. In SEK.

\begin{tabular}{lllllll} 
& \multicolumn{3}{c}{ Hotel A } & \multicolumn{3}{c}{ Hotel B } \\
\cline { 2 - 7 } & Yr1 & Yr2 & Yr3 & Yr1 & Yr2 & Yr3 \\
\hline BVAA (gross) & 121,175 & $-303,833$ & 61,158 & $3,862,591$ & $3,550,458$ & $7,297,991$ \\
Investment(discounted) & $-360,000$ & $-395,640$ & $-477,854$ & $-977,384$ & $-1,074,145$ & $-1,180,486$ \\
Total BVAA & $-238,825$ & $-699,473$ & $-416,606$ & $2,885,207$ & $2,476,313$ & $6,117,505$ \\
\hline
\end{tabular}

The results, presented as illustrative examples, clearly indicate substantial differences, as Hotel A presents a negative BVAA for all three years, while Hotel B could report a substantial BVAA for the same three years. The initial investment in the case of Hotel $A$ is resulting in a negative BVAA, even if the gross BVAA excluding this figure is positive in Yr1 and Yr3. Consequently, the inclusion of the initial investment produces quite different results.

\section{Discussion}

The complexity of calculating the brand value in relation to the market value has stopped 
several managers and owners from trying to calculate the value of affiliating (Carlbäck, 2012, O’Neill, 2004). This would not only be the case in the selection process of potential partner, but also in circumstances of taxation (separating real estate from intangible assets), financing, mergers, and acquisitions (Rushmore et al., 2013). In all these conditions a method of separating the intangible asset value from the real estate would affect the business, something which could be done with the BVAA-method. The method uses Tiwari's (2012) definition on brand value and focuses on the financial value of the brand, i.e. the affiliation and calculates the financial value for the hotel owner and for other stakeholders calculated on a NPV basis in accordance with Tollington (2002).

The results from the BVAA method will here be compared to previously used methods (O'Neill, 2004, Rushmore, 2001b). Since the investment costs associated with the adaptation are of importance in a consortium context (Carlbäck, 2012), the BVAA-method will give more comprehensive information regarding the financial issues connected to affiliating into a consortium. In Table 8 below, the different results for the two hotels for the three years are presented. The variation between the computed values is substantial. As the Rushmore-method (Rushmore, 2001b) primarily is used to extract the real estate value from the enterprise value, the intentions with the method is not the same as the O'Neillmethod (O'Neill, 2004) and the BVAA calculation method. The Rushmore method is based on the assumption that the fees reflect the value of affiliation. Thus the value of affiliation will always be positive (as long as the fees are positive) according to the Rushmore method.
All valuations in Table 8 are annual, i.e. they are based on figures relating to one specific year and consequently valid for that specific moment in time. For the O'Neill-method and the BVAA- calculation method the values are calculated with use of the cap rate. The overall value for the Rushmore-method has be computed using the cap rate as shown in Table 8.

The differences in brand value, as presented in Table 8, could certainly affect strategic decision making. The calculations for each method are based on the figures presented in Table 5. The brand value in Hotel A Yr1 fluctuates from SEK $-238,825$ (BVAA method) to SEK 1444,758 (Rushmore overall value) with the O'Neillmethod in between. The differences between the O'Neill results and the BVAA results are substantially smaller.

As the Rushmore method does not take the incremental revenue generated by the brand into consideration, it will produce a result which is usable mainly in a context where the objective is to separate real estate value from the total market value. For all three years the Rushmore method therefore produces positive results, which it is intended to do. The results will be relatively stable and predictable, based on contract stipulated royalties and fees, over the years compared to the other methods, where several factor will affect the outcome. These positive results are highly relevant for the affiliation, which could envisage a positive result, i.e. royalty payments from the affiliated hotel. The method does not focus on the performance of the hotel, nor the value created.

Hotel $B$ receives great value from its affiliation, more than MSEK 6, based on contribution Yr3, and is producing a substantial return on the

Table 8. Differences between three methods, based on separating the brand affiliation value from the market value (in SEK)

\begin{tabular}{lcccccc} 
& \multicolumn{3}{c}{ Hotel A } & \multicolumn{3}{c}{ Hotel B } \\
\cline { 2 - 7 } Year/ Method & Yr1 & Yr2 & Yr3 & Yr1 & Yr2 & Yr3 \\
\hline Rushmore (per year) & 173,371 & 124,169 & 144,001 & 890,238 & 906,66 & 877,72 \\
Rushmore (Overall value) & $1,444,758$ & $1,034,742$ & $1,200,008$ & $7,418,650$ & $7,555,500$ & $7,314,333$ \\
O'Neill(= gross BVAA) & 121,175 & $-303,833$ & 61,158 & $3,862,591$ & $3,550,458$ & $7,297,991$ \\
BVAA & $-238,825$ & $-699,473$ & $-416,606$ & $2,885,207$ & $2,476,313$ & $6,177,505$ \\
\hline
\end{tabular}


investment. Interestingly, the initial investments, which are of concern for independent hotel owners seeking alternatives, is affecting less than the hotel owners anticipated. Although the present value of Hotel B's investment is SEK 1,180,000 compared to SEK 434,000 for Hotel A in Yr3, the former is creating a far higher BVAA.

As shown in Table 8, the cost related to affiliating (such as royalty and booking fees) used in the Rushmore-method is moderate in the case of Hotel A (SEK 144,000) and considerably higher in the case of Hotel $B$ $(887,000)$ for Yr3. At the same time, the benefits produced are very different - in the case of Hotel B the cost is only $13 \%$ of the value created. As the intention here is to create a method to calculate a BVAA for a hotel in a consortium, the treatment of the membership fees will not suffice, it is clearly necessary to look at the contribution created as well. A value is created and this value will be of utmost importance for any hotelier contemplating affiliating. The initial investment is affecting the end result, and as the aim is to calculate the BVAA in a way which makes it possible for the hotel owner to evaluate the options, or current situation, this needs to be included in order to produce valid results.

A method especially developed for the consortium is the main contribution from this study. Primarily as very little research is done on consortium companies and consortium members (Carlbäck, 2012). This is achieved by including the initial investment associated with the adaptation process. Another factor is to add this to the NPV of the contribution achieved from affiliating. The individual hotel owners will now be able to measure the contribution and value created. The hotel will buy into a brand and the adaptation process could be costly and therefore affect the overall feasibility of the project.

Even if it primarily is a matter of matching a hotel to an affiliation, from various perspectives, the method presented here could produce figures which indicate major discrepancies between what the hotel owner pays and what they get from the money invested in such a venture. As an illustration, for Hotel A, alternative routes would be advisable as the membership is producing a negative BVAA. Could the money spent on the affiliation possibly be used more productively in another way - marketing efforts, up-grading of facilities, new management or a change to a, for this property, more suitable affiliation?

By looking at the key performance indicators for each hotel presented in Table 1 , it is possible to identify the affects these will have on the BVAA. Significant are the substantial improvements in the key performance indicators and NOI for Hotel B during the period. This could be identified as attributable to the contribution associated with the brand, which consequently produces a positive BVAA. In this case it is evident that the key performance indicators are affecting the valuations for the BVAA. A better ADR (average daily rate) for hotel $B$ generates a positive contribution attributable to affiliation for all three years. This stresses the importance the affiliation will have on the business, primarily as a revenue generator and as a value driver, i.e. the affiliation should be able to produce better figures for the participating hotels. If not, they cannot justify the fees and royalties payable. This is in line with previous research, a study by O'Neill \& Carlbäck (2011) covering 51,000 hotels in the US, where affiliated hotels produced better NOI and occupancy rate than independent hotels.

As positive key performance indicators are results of a membership in a consortium and will affect the BVAA-value, it would be advisable to take this into consideration when choosing an affiliation. What do $\mathrm{I}$, as an hotelier, need to improve in my business, and can this affiliation, with its business plan, fulfil this? The method could be used to simulate different scenarios in the decision making process as the degree of involvement varies between the different consortium companies (Lee \& Jeong, 2014).

It is possible to calculate the BVAA for hotels in a consortium context. The contribution of this study is the inclusion of investment relating to the adaptation process, i.e. get the hotel up to the affiliation's requested standards something perceived by independent hotel 
owners as a major obstacle to affiliating (Carlbäck, 2012).

This article is focusing more on issues which are relevant for the independent hotel owners seeking strategic alternatives for the future (Ivanova \& Ivanov, 2015b). By using the BVAA method, the foundations for important decision could be enhanced. It gives the opportunity to evaluate a membership in a consortium from a financial perspective - to evaluate if the invested money (fees, royalties and initial investment) are producing a fair return.

The results also support Tiwari's (2010) definition of brand value, which this method is based on. The measurement is the net present value of future cash flows from a branded product minus the net present value of future cash flows from a similar unbranded product what the brand is worth to management and shareholders (Tiwari, 2010).

\section{Managerial Applications}

The BVAA-method offers managers, owners or decision makers a method to better understand the pros and cons of affiliating. In both hotels presented in this article, the owners or managers expressed only a vague knowledge as to what benefits the membership produced.

It is apparent that the BVAA can vary considerably between different affiliations. While the membership for hotel $A$ is producing a negative BVAA, the case for hotel $B$ is the reverse. There would be several factors to take into consideration before one can draw any major conclusions as to why this is the case. Based on the results, using the BVAA method, hotel $A$ would have to consider alternative strategic possibilities, as the money invested in a membership is not producing an acceptable return (and during all three years the membership is costing money). As hotel $A$ is a well-known business with a clear market presence, a first suggestion for an alternative future would be to discontinue the agreement with the affiliation, or alternatively look for a better suited affiliation. This would partly depend on the affiliations ability to create a positive BVAA and partly on how well the two entities match in a business perspective.
The method will also aid hoteliers and managers in their strategic business planning as different alternatives could be compared before any decisions are made. This would then constitute one aspect, the financial, which could be used in connection with several other aspects of importance in the decision process. Membership in an affiliation could also improve marketing activities, add economies of scale in purchasing hotel supplies and recruitment processes etc. Expected results could further be compared to financial outcomes in order to facilitate more efficient corrective actions. The industry professionals could measure as to what extent affiliation would be a performance booster or if it would add market value to their business in the event of refinancing, disinvesting, mergers and acquisitions. The affiliation stakeholders could benefit from a method suitable to adjust their offering to independent hotels and therefore be more attractive and enhance their performance and growth.

Methods would both be beneficial for the hotel owners searching for information to enhance the strategic decision making, and for the consortium trying to attract new members. A greatly improved BVAA would produce a better market value for the hotel owner. By communicating this, the affiliations would have better possibilities to attract new members to a consortium and in a long term also be able to adjust the fees and royalty payments accordingly.

A more solid knowledge of BVAA-creation within organisations would open up the discussion regarding new ways to compute the royalties and membership fees. A higher BVAA-value created, based on the brand, could impose higher royalty payments and produce incentives for both the organisation and the individual hotels, not to mention the argumentation for actually joining a consortium.

\section{Limitations and Directions for Further Research}

The results from this study should be interpreted with caution, and the method should be tested and evaluated in more circumstances before one can draw conclusions. Even if the method in itself would be universal, 
considerations must be taken to the fact that the hotels used as illustrations are based in the Swedish market and the results may vary between different markets as well as various affiliations. One of the affiliations is Swedenbased and will operate in accordance with Swedish standards and practices. But as the hotel scene is homogenised, the results produced with the BVAA-method should be indicative for similar markets in other economies. Further, it should be taken into consideration that the illustration is based on two hotels with their own individual features and functions. And as it previously has been discovered (O'Neill \& Carlbäck, 2011) the general economic climate will affect, not only the hotels' result, but also the value of the brand. A similar study over a prolonged period of time (including a recession and an economic upturn) would also produce relevant results, better indicating the possible value of a membership under certain economic conditions.

The use of income statements for the two hotels, where entries related to the affiliation are clearly presented, facilitates a straight forward identification of gross profit and incremental cost attributable to the affiliation. The figures related to the historic adaptation process present a different challenge, as some of the items, such as upgrading of certain facilities, i.e. bath rooms could have a residual value even in a case of a termination of the affiliation-contract.

One way to further test the method and enhance the knowledge would be similar studies in other markets, with larger selections or based on a selection within one organisation. This could provide more information regarding the actual BVAA within a specific organisation and the means to compare between organisations. It might well be that the BVAA greatly varies in any given chain, and factors such as location, size and amenities play an important role as to the magnitude of BVAA.

\section{References}

Ailawadi, K., Lehmann, D., Neslin, A.: (2003) Revenue Premium as an Outcome Measure of Brand Equity. Journal of
Marketing: October 2003, Vol. 67, No. 4, pp. 1-17

Andersson, T. D., Carlsen, J., \& Getz, D. (2002). Family business goals in the tourism and hospitality sector: case studies and cross-case analysis from Australia, Canada, and Sweden. Family Business Review, 15(2), 89-106.

Ayazlar, G., (2016) Entry modes: Marketing consortium, in: Ivanova, M. (Ed.), Ivanov, S. (Ed.), Magnini, V. (Ed.). The Routledge Handbook of Hotel Chain Management. London: Routledge.

Bailey, R. (2007). UK hotel industry brand equity: Its meaning and uses for brand management. Sheffield Hallam University, Sheffield.

Bailey, R., \& Ball, S. (2006). An exploration of the meanings of hotel brand equity. The Service Industries Journal, 26(1), 15-38.

Cai, L., \& Hobson, P. (2004). Making Hotel Brands Work in a Competitive Environment. Journal of Vacation Marketing, 10(3), 197-208.

Carlbäck, M. (2012). Strategic Entrepreneurship in the Hotel Industry - the Role of Chain Affiliation Scandinavian Journal of Hospitality and Tourism, 12(4), 349-372.

Carlbäck, M. (2010). An analysis of the measurement and possible use of intangible asset value in the Swedish hotel and restaurant industry. 10th Manufacturing Accounting Research Conference, Ghent (Belgium), 20-23 June 2010.

Carlbäck, M. (2016). Independent or flagged? The decision to affiliate to a chain. The Routledge Handbook of Hotel Chain Management, 385.

Dev, C., Brown, J., \& Zhou, K. Z. (2007). Global Brand Expansion: How to Select a Market Entry Strategy. Cornell Hospitality Quarterly, 48(1).

Hasni, M.J.S., Salo, J., Naeem, H., Abbasi, K.S. (2018). Impact of internal branding on customer-based brand equity with mediating effect of organizational loyalty: An empirical evidence from retail sector. International Journal of Retail and Distribution Management. Volume 46, Issue 11-12, Pages 1056-1076

Häggström, R. (2012). Intangible Assets and Hotel Value. Gothenburg University, Gothenburg. 
Ivanova, M. \& Ivanov, S. (2015) Affiliation to hotel chains: Hotels' perspective, Tourism ManagementPerspectives, 16(Oct), 148-162 Ivanova, M. \& Ivanov, S. (2015b) The Nature of Hotel Chains: An Integrative Framework. International Journal of Hospitality \& Tourism Administration, 16 (2), 122-142

Ivanova, M. \& Ivanov, S. (2016) Hotel chains' conceptual models, in: Ivanova, M. (Ed.), Ivanov, S. (Ed.), Magnini, V. (Ed.). The Routledge Handbook of Hotel Chain Management. London: Routledge.

Kasanen, E., Lukka, K. and Siitonen, A. (1993) 'The Constructive Approach in Management Accounting research', Journal of Management Accounting Research, Vol. 5, pp.243-264.

Lee, S., Jeong, M., (2014), Enhancing online brand experiences: An application of congruity theory. International Journal of Hospitality Management. Volume 40, July 2014, Pages 49-58

Manthiou, A., Kang, J., Sumarjan, N., Tang, L., (2015). The Incorporation of Consumer Experience into the Branding Process: An Investigation of Name-Brand Hotels. International Journal of Tourism Research. Volume18, Issue 2, Pages 105-115

O'Neill, J. W., \& Carlbäck, M. (2011). Do brands matter? A comparison of branded and independent hotels' performance during a full economic cycle. International Journal of Hospitality Management, 30(3), 515-521.

O'Neill, J. W., \& Mattila, A. S. (2004). Hotel Branding Strategy: It's Relationship to Guest Satisfaction and Room Revenue. Journal of Hospitality \& Tourism Research, 28(2), 156-165.

O'Neill, J. W., \& Mattila, A. S. (2010). Hotel Brand Strategy. Cornell Hospitality Quarterly, 51(1), 27-34.

Lloyd-Jones, A. (2010). Comparative Capitalization Rate Study. New York: HVS.

Martorell Cunill, O. (2006). The Growth Strategies of Hotel Chains (Vol. 1). New York: The Haworth Hospitality Press.

O'Neill, J. W. (2004). An Automated Valuation Model for Hotels. Cornell Hotel and Restaurant Administration Quarterly, 45(3), 260-268.

O'Neill, J. W., \& Belfrage, E. E. (2005). A Strategy for Estimating Identified Intangible
Asset Value: Hotels Affiliation Contribution. The Appraisal Journal, Winter 2005 O'Neill, J. W., \& Xiao, Q. (2006). The role of brand affiliation in hotel market value. Cornell Hotel and Restaurant Administration Quarterly, 47(3), 210-223.

Prasad, K., \& Dev, C. (2000). Hotel Brand Equity. Cornell Hotel and Restaurant Administration Quarterly, 41(3), 22-31.

Rivet, V. (2011). The Challenges of Repositioning an International Brand: a Case Study on the Hospitality Industry. Escola de Administração de Empresas de São Paulo, Sao Paolo.

Roper, A. (2018). Vertical Disintegration in the Corporate Hotel Industry. London: Routledge

Rushmore, S. (2001a). Six things to consider before obtaining a hotel franchise. Hotels (September 2001).

Rushmore, S. (2001b). What do hotel franchises actually cost? Hotels, 36.

Rushmore, S. (2004). A case for being independent. Hotels (February), 22.

Rushmore, S., O'Neill, J. W., \& Rushmore, S. J. (2013). Hotel Market Analysis International Issues and Software Applications. Chicago: Appraisal Institute.

Seric, M., Gil-Saura, I., Eugenia Ruiz-Molina, M., (2014). How can integrated marketing communications and advanced technology influence the creation of customer-based brand equity? Evidence from the hospitality industry. International Journal of Hospitality Management, Volume 39, May 2014, Pages 144-156

Seric, M., Mikulić, J., Gil Saura, I. (2018). Exploring relationships between customerbased brand equity and its drivers and consequences in the hotel context. An impact-asymmetry assessment. Current Issues in Tourism. Volume 21, Issue 14, Pages 1621-1643

Standfield, K. (2005). Intangible Finance Standards. Burlington, MA: Elsevier Academic Press.

Taylor, P. S. (1995). Choosing a Flag. Lodging Hospitality (July), 24-27.

Tiwari, M. (2010). Separation of Brand Equity and Brand Value. Global Business Review, 11(3), 421-434.

Tollington, T. (2002). Brand Assets. Chichester: John Wiley \& Sons Ltd. 